\title{
MPPT of Magnus Wind System with DC Servo Drive for the Cylinders and Boost Converter
}

\author{
Maro Jinbo, ${ }^{1,2}$ Felix Alberto Farret, ${ }^{1}$ Ghendy Cardoso Junior, ${ }^{1}$ \\ Daniel Senter, ${ }^{2}$ and Marcelo Franklin Lorensetti ${ }^{2}$ \\ ${ }^{1}$ Department of Electrical Engineering, Federal University of Santa Maria (UFSM), 97105-900 Santa Maria, RS, Brazil \\ ${ }^{2}$ Department of Automation and Control Engineering, Federal Institute of Santa Catarina (IFSC), 89813-000 Chapecó, SC, Brazil \\ Correspondence should be addressed to Maro Jinbo; maro@ifsc.edu.br
}

Received 5 March 2015; Revised 30 June 2015; Accepted 7 July 2015

Academic Editor: Adrian Ilinca

Copyright (C) 2015 Maro Jinbo et al. This is an open access article distributed under the Creative Commons Attribution License, which permits unrestricted use, distribution, and reproduction in any medium, provided the original work is properly cited.

\begin{abstract}
This paper presents an algorithm MPPT (Maximum Power Point Tracking) for a Magnus wind system with a DC servo drive system (DC drive and BLDC motor) to rotate the turbine cylinders. The optimal cylinders rotation is the one to deliver the maximum power extracted from the wind tracked by fixed and adaptive step HCC (Hill Climbing Control) acting on the servo drive. The proposed wind system consists of a PMSG (Permanent Magnet Synchronous Generator), a three-phase diode rectifier, a DC/DC (boost) converter, and a resistive load. Furthermore, the boost converter acts with the fixed step HCC algorithm to track the maximum power operating point. Therefore, the MPPT for a Magnus wind system requires both tracking for the optimal cylinder speed and the optimal generator speed.
\end{abstract}

\section{Introduction}

The Magnus wind turbine has rotating cylinders rather than the conventional blade wind turbines as shown in Figure 1. The angular velocity $\Omega_{1}$ is the rotational speed of the turbine and $\Omega_{2}$ is the rotational speed of the cylinders. Its operation is based on the physical principle known as "Magnus effect."

Detail (a) in Figure 1 is the front portion of the hub where the DC servo drive system (DC servo drive and BLDC motor) is located. A gear system transmits the rotation from the BLDC motor to the cylinders, detail (b).

A numerical simulation by Imai and Kato [1] was used to compare the performance of a smooth cylinder and a cylinder with 6 spiral fins as shown in Figure 2 (CFD-Computational Fluid Dynamics).

Figure 2(b) represents the air flow around a smooth rotating cylinder with the same diameter of the spiral fin cylinder represented in Figure 2(a). The featured points called "points of separation" are regions where there is a cylinder wall detachment from air flow.

Figure 2(c) illustrates the air flow pattern around the cylinder with spiral fin arranged in accordance with
Figure 2(a). It is noticeable that the air flow detachment at the bottom of the cylinder with spiral fin is in a postponed point. This fact provides a larger surface extension on the lower face of the rotating cylinder with relatively less pressure than the upper face, and thus the lift force on the upper face is stronger when compared to the cylinder without fins.

A cylinder with radius $R$ rotating with an angular velocity $\Omega$, immersed in a fluid of density $\rho$, is shown in Figure 3, with a laminar fluid velocity $U_{\infty}$. Theoretically, the wind rotor is subject to a lift force in the perpendicular direction to the fluid flow called $F_{Y}$ lift (lift force) and $F_{X}$ drag (drag force), a phenomenon known as Magnus effect [2,3]. Theoretically the drag force $F_{X}$ should be zero, but it has been proven experimentally that this value is not null and increases with the increasing relative velocity of the cylinder surface [3].

Registers of the first prototypes of Magnus wind turbines are not new [4]. In 1926 Flettner built a horizontal-axis wind turbine with four blades, where each blade was a tapered cylinder driven by an electric motor. The cylinders (blades) were $5 \mathrm{~m}$ long and $0.8 \mathrm{~m}$ in diameter at the midpoint. The experiment used a $20 \mathrm{~m}$ diameter rotor on a $33 \mathrm{~m}$ tower, with a rated power of $30 \mathrm{~kW}$ at a wind speed of $10 \mathrm{~m} / \mathrm{s}$. 


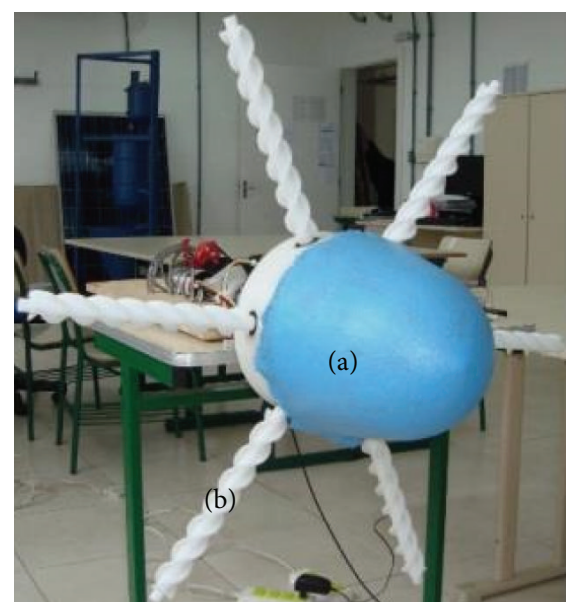

Figure 1: Magnus effect wind turbine [25]. (a) Hub. (b) Cylinder.

In 1983, a private entrepreneur in California constructed a Magnus-type wind turbine of the barrel blade type, with a $17 \mathrm{~m}$ diameter, of a rated capacity of $110 \mathrm{~kW}$. The unit was later moved to the wind test site of Southern California Edison, which was located in San Gorgonio Pass.

Recently, in 2007, a Japanese company by joint efforts between industry, government, and universities has developed and commercially launched a Magnus wind turbine [5]. The cylinders of this Magnus turbine have two important characteristics that became commercially feasible, one spiral fin and an end cap for an enhanced Magnus effect [6].

Experiments were conducted also in Russia with prototypes of Magnus wind turbines in a wind tunnel. It was shown that the Magnus turbine even at wind speeds of $2 \mathrm{~m} / \mathrm{s}$ presents a power coefficient enough to generate a net power output and take advantage of these low wind speeds. This turbine can be operated up to $40 \mathrm{~m} / \mathrm{s}$ wind speed well above the upper limit of the conventional turbines [7-9].

\section{Magnus Effect Wind Turbine}

2.1. Mechanical Power of the Magnus Wind Turbine. Figure 4 shows a Magnus effect wind turbine, where $N$ is the number of rotating cylinders; $R_{1}$ is radius of the rotor [m]; $\Omega_{1}$ is turbine speed $[\mathrm{rad} / \mathrm{s}] ; R_{2}$ is radius of the cylinder $[\mathrm{m}] ; \Omega_{2}$ is cylinder's speed $[\mathrm{rad} / \mathrm{s}] ; U_{\infty}$ is laminar wind speed $[\mathrm{m} / \mathrm{s}]$; and $\rho$ is air density $\left[\mathrm{kg} / \mathrm{m}^{3}\right]$.

The tip speed ratio (TSR or $\lambda_{1}$ ) is the ratio of the tangential velocity of the blade or cylinder (at the tip) under an undisturbed wind speed, according to [10]

$$
\lambda_{1}=\frac{\Omega_{1} \cdot R_{1}}{U_{\infty}} .
$$

The relative speed of the rotating cylinders $\lambda_{2}$ is the ratio of the tangential velocity of the cylinder under an undisturbed wind speed, according to $[11,12]$

$$
\lambda_{2}=\frac{\Omega_{2} \cdot R_{2}}{U_{\infty}} .
$$

Therefore, the mechanical power extracted from the wind by the Magnus turbine is represented by [10-14]

$$
P=0.5 \cdot \rho \cdot U_{\infty}^{3} \cdot \pi \cdot R_{1}^{2} \cdot C_{P}
$$

The analytical equation (4) is related to the power coefficient $C_{P}$ of the Magnus turbine and it was obtained based on the principles of fluid dynamics and the theory of momentum of blade elements (BEM-Blade Element Momentum Theory) neglecting the influence of other relevant factors at the turbine power output such as the drag force, losses at the cylinder ends, interaction between cylinders, and effects of the hub diameter. Moreover (4) was obtained based on the $C_{P}$ values obtained experimentally from a model closer to reality $[11,12]$. The theoretical limit of the power coefficient for Magnus wind turbines is $C_{P}=0.593$ :

$$
\begin{aligned}
C_{P}= & \frac{N \cdot \Omega_{1} \cdot \Omega_{2} \cdot R_{2}^{2}}{2 \cdot U_{\infty}^{2}} \\
& \cdot\left(1+\sqrt{1-\frac{N \cdot \Omega_{1} \cdot \Omega_{2} \cdot R_{2}^{2}}{U_{\infty}^{2}}}\right) .
\end{aligned}
$$

2.2. Hill Climbing Control (HCC) Algorithm. The HCC algorithm with fixed step performs the tracking of the maximum point (MP) on the net power curve $P_{\text {net }}$ by incrementing or decrementing the voltage reference $V_{\text {ref }}$ at fixed steps $\Delta V_{\text {fixed }}$. The algorithm is always searching for the MP as shown in Figure 5. A relatively large step can result in a shorter time to reach the top of the curve but also results in larger oscillations around the MP $[15,16]$.

An HCC algorithm with adaptive step performs the tracking of the maximum point (MP) on the net power curve $P_{\text {net }}$ by incrementing or decrementing the voltage reference $V_{\text {ref }}$ (5) with an adaptive value $\Delta V_{\text {adp }}$ (6). The algorithm is always searching for the MP as shown in Figure 6. The value of $\Delta V_{\text {adp }}$ decreases when the output power is closer to the MP, thus reducing the oscillations around this point according (6). In (6) the symbol $\varepsilon$ is a constant infinitesimal parameter:

$$
\begin{aligned}
\left(V_{\text {ref }}\right)_{k} & =\left(V_{\text {ref }}\right)_{k-1} \pm \Delta V_{\text {adp }}, \\
\Delta V_{\text {adp }} & =\varepsilon \cdot \Delta P_{k} \cdot \Delta V_{k} .
\end{aligned}
$$

2.3. The MPPT for a Magnus Wind Turbine. The mechanical power $P_{\text {mec }}$ produced by a Magnus wind turbine, as well as conventional wind turbines, is the product of the torque $T(\mathrm{~N} \cdot \mathrm{m})$ and the rotation speed of the turbine $\Omega_{1}$ (rads/s) according to (7). There is an optimal rotational speed producing the maximum mechanical shaft power. Therefore, it is necessary to track this optimal rotational turbine speed (MPPT) [17-19]:

$$
P_{\mathrm{mec}}=T \cdot \Omega_{1} .
$$

Figure 7 shows the typical mechanical power curves produced by a Magnus turbine by increasing $\lambda_{2}$ (relative rotation of the cylinders) at a given constant $\lambda_{1}$ (TSR of the turbine). For each wind speed is depicted the relative cylinder rotation 


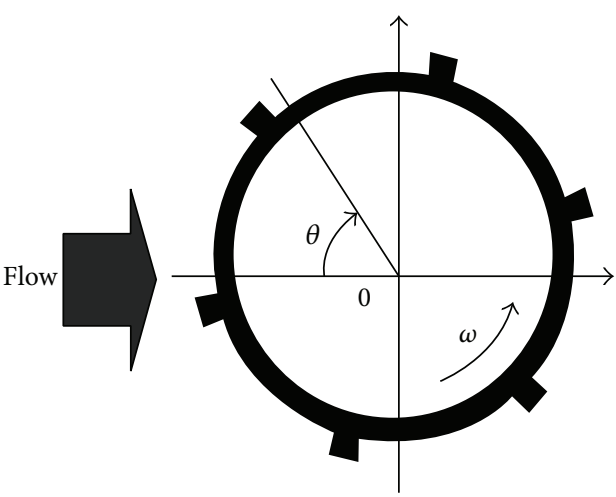

(a)

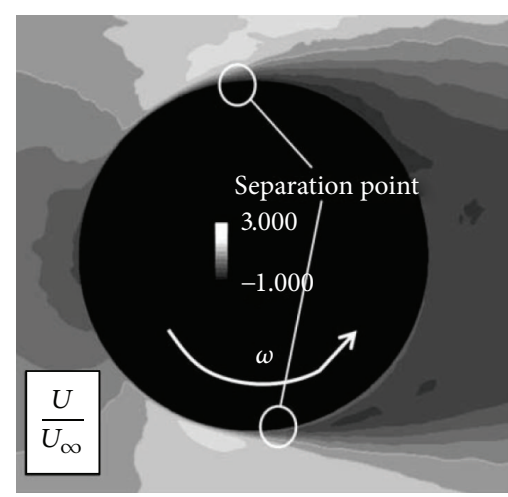

(b)

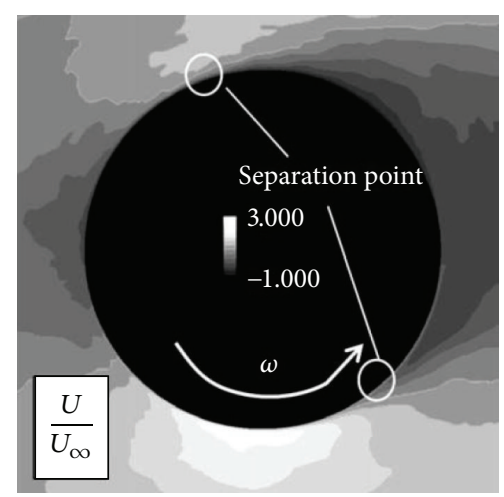

(c)

FIGURE 2: Numerical simulation in CFD [1] of a rotating cylinder. (a) Cylinder with 6 spiral fins. (b) Smooth cylinder. (c) Cylinder with spiral fins.

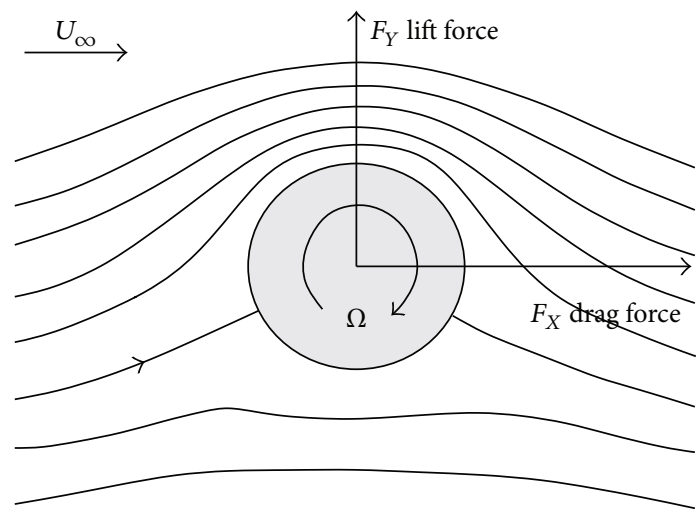

FIGURE 3: Rotating cylinder immersed in a fluid [13]

to provide the maximum mechanical power from the wind [20]. The Magnus wind system tracks the net power $P_{\text {net }}(8)$ on the turbine shaft, discounting the power consumed $P_{\text {cons }}$ by the driving system (servo drive DC and BLDC motor) of the rotating cylinder:

$$
P_{\text {net }}=P_{\text {mec }}-P_{\text {cons }} \text {. }
$$

\section{The Proposed Magnus Wind System}

The wind system proposed in Figure 8 consists of a mathematical model of the Magnus turbine according to (3) and (4), the DC servo drive system (inverter bridge and BLDC motor), a PMSG generator, a three-phase rectifier, a boost converter DC/DC, and a resistive load. The goal of the proposed wind system is to demonstrate the maximum power extraction from the wind to be dissipated in a resistive load.

The $V_{\mathrm{dc}}$ is voltage source at the input of the threephase bridge inverter with 6-IGBT (Insulated Gate Bipolar Transistor). This bridge inverter drives the BLDC motor.

The IGBT switches in the inverter bridge are closed in pairs in a sequence according to Table 1 consisting of 6 steps for a complete rotation of the BLDC motor.

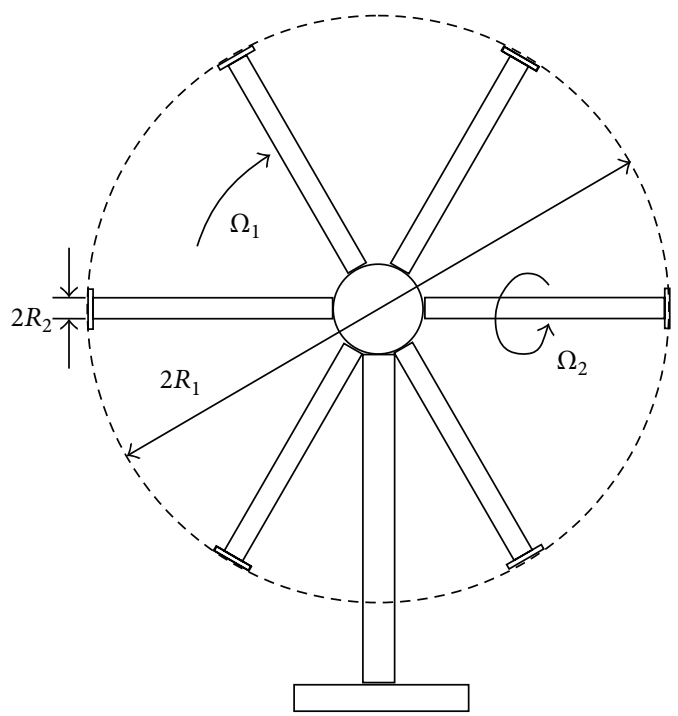

FIgURE 4: Magnus wind turbine.

TABLE 1: Switching stages of the inverter bridge.

\begin{tabular}{|c|c|c|c|c|c|}
\hline Stage & 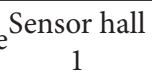 & $\begin{array}{c}\text { Sensor hall } \\
2\end{array}$ & $\begin{array}{c}\text { Sensor hall } \\
3\end{array}$ & $\begin{array}{l}\text { Switch } \\
\text { IGBTs }\end{array}$ & $\begin{array}{c}\text { Current in } \\
\text { the coil }\end{array}$ \\
\hline 1 & 1 & -1 & 0 & S1 e S4 & $A \rightarrow B$ \\
\hline 2 & 1 & 0 & -1 & S1 e S6 & $\mathrm{A} \rightarrow \mathrm{C}$ \\
\hline 3 & 0 & 1 & -1 & S3 e S6 & $\mathrm{B} \rightarrow \mathrm{C}$ \\
\hline 4 & -1 & 1 & 0 & S2 e S3 & $\mathrm{B} \rightarrow \mathrm{A}$ \\
\hline 5 & -1 & 0 & 1 & S2 e S5 & $\mathrm{C} \rightarrow \mathrm{A}$ \\
\hline 6 & 0 & -1 & 1 & S4 e S5 & $\mathrm{C} \rightarrow \mathrm{B}$ \\
\hline
\end{tabular}

The signals from the three hall effect sensors consist of square waves $(-1,0,1) 120^{\circ}$ out of phase applied to a circuit consisting of AND and NOT logic gates providing the switching sequence for the inverter bridge switches driving the BLDC motor rotation. 


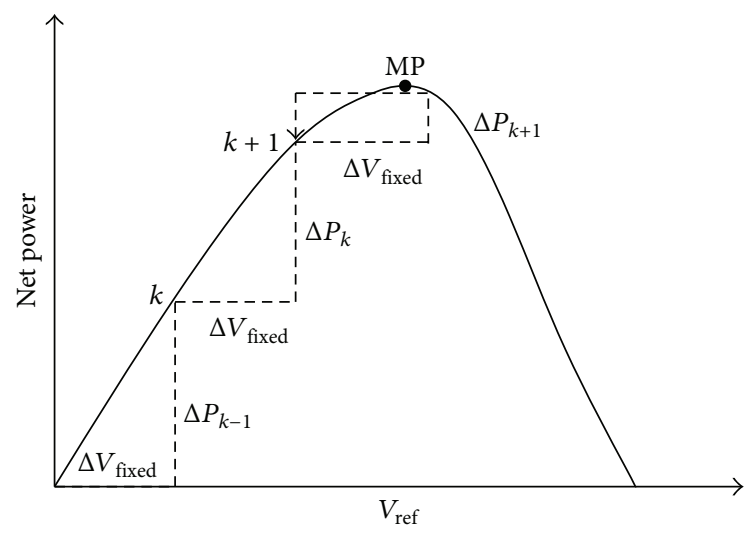

Figure 5: Hill Climbing Algorithm with fixed step.

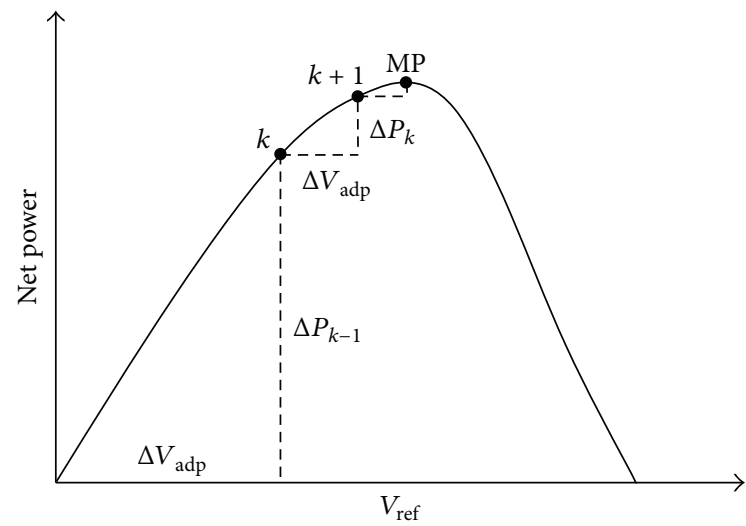

Figure 6: Hill Climbing Algorithm with adaptive step.

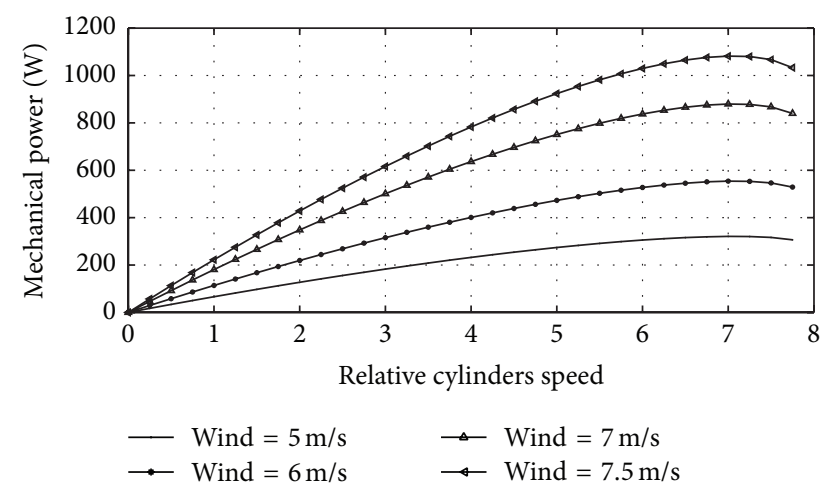

Figure 7: Mechanical power versus $\lambda_{2}$.

The torque and motor speed can be controlled by varying the average voltage across the terminals $(\mathrm{ABC})$ of the BLDC motor coils. This variation is used for the pulse width modulation $\left(\mathrm{PWM}_{1}\right)$. The average voltage delivered to the coils is driven by modulating the duty cycle. Consequently, the BLDC motor speed also changes.

The wind system proposed in this paper measures the electrical power delivered to the inverter bridge. This power is identified by $P_{\text {cons }}$, that is, the power consumed to rotate the turbine cylinders. The electric power measured across the diode rectifier output is the electrical power generated, called $P_{\text {gen }}$. The difference between the respective generated powers $P_{\text {gen }}$ and $P_{\text {cons }}$ is the net power $P_{\text {net }}(8)$.

The block "MPPT cylinders" shown in Figure 8 represents the HCC algorithm tracking the optimal cylinder speed $\Omega_{2}$ to provide the maximum net power $P_{\text {net }}$ extracted from the turbine. Whenever the net power is negative, the algorithm performs a fixed step and when the net power is positive the algorithm performs an adaptive step.

The block "MPPT boost" represents the HCC algorithm with fixed step tracking the maximum electrical power by scanning the boost converter duty cycle.

Figure 9 shows the control algorithm flowchart for the rotating cylinders. Initially, the wind speed is read, which is compared to wind speed reference denoted by wind $\mathrm{min}_{\min }$. For winds below this value, the cylinder rotation is kept static avoiding unnecessary waste of energy. When the wind speeds are above this value, the control generates a positive net power step which assures to the turbine the necessary starting interval. From this point onwards, the control algorithm reads the net current power $P_{k}$ and calculates the difference $\Delta P$ between the power $P_{k}$ and the previous $P_{k-1}$. It also measures the difference between the voltage reference $\Delta V_{\text {ref }}$ of the $\mathrm{PWM}_{1}$ resulting from the difference between $\Delta V_{\text {ref }(k)}$ (the current) and $\Delta V_{\text {ref }(k-1)}$ (the previous voltage). If $P_{k}$ (net power current) is negative, the controller commands an increment $\Delta V_{\text {fixed }}$ (fixed step) to the voltage reference $V_{\text {ref }}$. If $P_{k}$ remains negative for longer than the predefined period, $t_{w}$, the cylinder driver is blocked with a $V_{\text {ref }}=0$ in order to avoid wasting energy. If $P_{k}$ is positive, the HCC algorithm (adaptive step) increments and decrements $V_{\text {ref }}$ with a step $\Delta V_{\text {adp }}$ aiming at tracking the maximum power point.

3.1. DC Servo Drive. The DC servo drive system (inverter bridge and BLDC motor) drives the cylinder rotation through the gear train system (gear crown and gear pinion).

The electric power generated $P_{\text {gen }}$ is measured across the diode rectifier output. The power consumed $P_{\text {cons }}$ by the DC servo drive system is measured across the $V_{\mathrm{dc}}$ power supply output. The net power $P_{\text {net }}$ is obtained from (8) and transmitted to the turbine hub by special collector rings conducting power and control signals.

The "MPPT cylinders" block output generates the reference signal to the $\mathrm{PWM}_{1}$ in order to switch the inverter bridge driving the DC servo system. The switching sequence of the three-phase inverter is defined by 3 signals coming from the hall sensors fitted on the brushless motor and logic gates AND and NOT [21].

The torque produced by the turbine is transmitted to the PMSG generator through a gear box.

3.2. DC/DC Boost Converter. The static converter consists of an uncontrolled three-phase rectifier, the $L_{f} C_{f}$ filter, a $\mathrm{DC} / \mathrm{DC}$ boost converter, and a resistive load, to dissipate the maximum electrical power. The boost converter shown in Figure 8 comprises a switch $S$, a diode $D_{1}$, and an inductance $L$. The main feature of this boost converter is to produce an output voltage $V_{o}$ higher than the input voltage $V_{\text {in }}$. Across the 


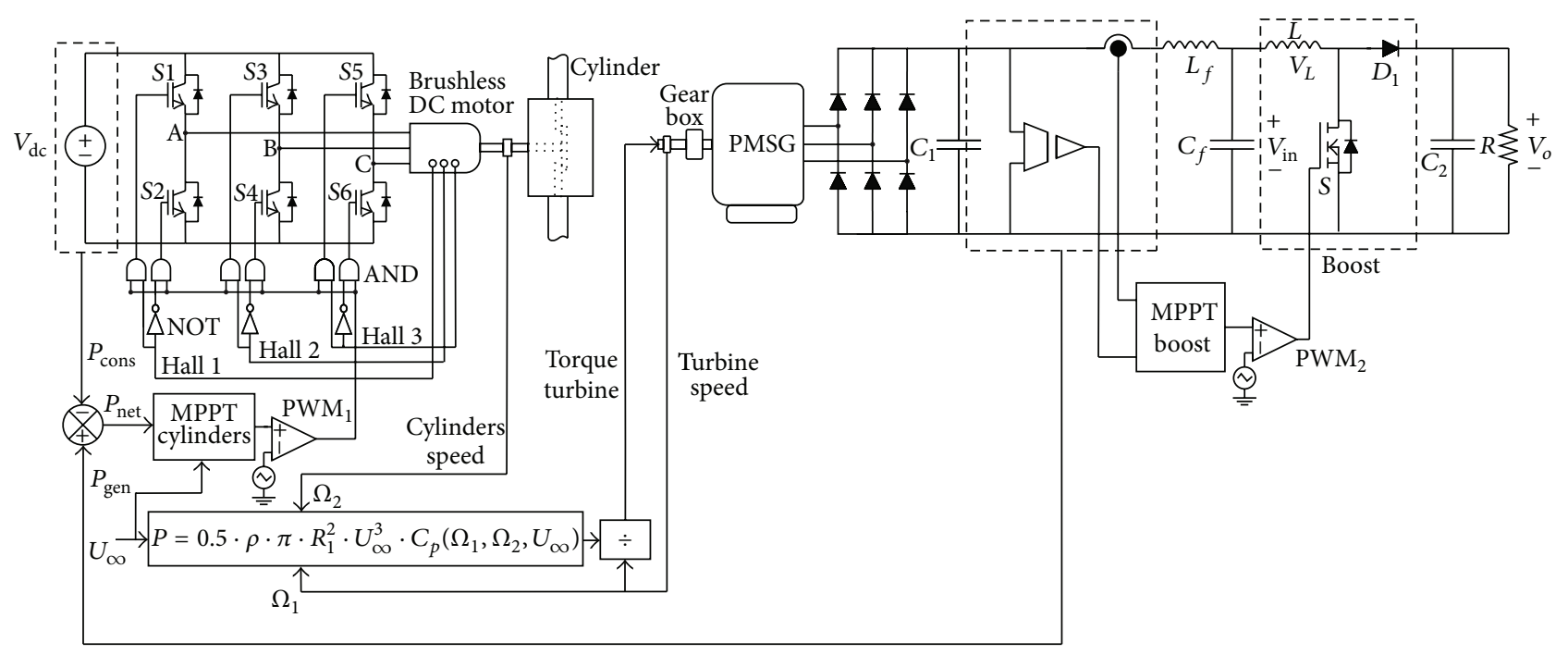

Figure 8: Proposed Magnus wind system.

PMSG generator output there is a three-phase uncontrolled bridge rectifier and a capacitor filter $C_{1}$. The purpose of the capacitor $C_{1}$ is to produce a smoother output voltage. The filter $L_{f} C_{f}$ is also coupled to make smoother input current and input voltage across the boost converter terminals.

The boost converter parameters are as follows: $V_{\text {in }}=$ input average voltage boost; $V_{o}=$ output average voltage boost; $V_{\mathrm{pk}}=$ line-to-line peak voltage across the rectifier; $L=$ boost inductor; $I_{L}=$ inductor current through the boost terminals; $I_{0}=$ load average current; $D=$ duty cycle; $T_{s}=$ switching period; $\Delta i_{L}=$ inductor ripple current; $P_{\text {in }}=$ boost power input; and $P_{o}=$ load power output.

The "MPPT boost" block in Figure 8 also represents the HCC algorithm (Hill Climbing Control with fixed step) tracking the optimal duty cycle " $D$ " of the boost converter delivering the maximum electrical power to the resistive load. The conversion ratio of the boost " $M$ " is given by [22]

$$
M(D)=\frac{V_{o}}{V_{\text {in }}}=\frac{1}{1-D} .
$$

The boost converter operating in continuous conduction mode (CCM) has two operation stages. The first step is the magnetization of the inductor $L$ and the second is its demagnetization. During the magnetizing interval the current slope across the magnetizing inductance $L$ is given by

$$
\frac{d}{d t} i_{L}(t)=\frac{{ }^{v} L(t)}{L}=\frac{V_{\text {in }}}{L} .
$$

During the magnetizing interval the current variation through the inductor $\Delta i_{L}$ is expressed by the current slope the multiplied by the time interval:

$$
\begin{aligned}
& 2 \cdot \Delta i_{L}=\frac{V_{\text {in }}}{L} \cdot D \cdot T_{S} \\
& \therefore \Delta i_{L}=\frac{V_{\text {in }}}{2 \cdot L} \cdot D \cdot T_{S},
\end{aligned}
$$

$$
L=\frac{V_{\text {in }}}{2 \cdot \Delta i_{L}} \cdot D \cdot T_{S},
$$

where $\Delta i_{L}$ is the ripple current through the inductor $L$.

Expression (12) determines the value of magnetizing inductance $L$ for the desired current ripple. When the converter is operating at CCM, that is, the current does not reach zero within the demagnetization range and to be valid the static gain of $M(D)$, it is necessary to have a current ripple smaller than the average current through the inductor [22]. That is,

$$
\Delta i_{L}<I_{L}
$$

Considering lossless ideal components, it can be said, therefore, that the input and output powers from the boost converter are equal; that is,

$$
\begin{gathered}
P_{\text {in }}=P_{o} \\
\therefore V_{\text {in }} \cdot I_{L}=V_{o} \cdot I_{o},
\end{gathered}
$$

where $I_{L}$ is the input current of the boost converter.

The output current $I_{o}$ from the boost converter can be obtained from the output voltage and resistance $R$ as

$$
I_{o}=\frac{V_{o}}{R} .
$$

The load resistor $R$ sets the output power range of the boost converter. Resistor $R$ defines a valid range for the duty cycle. As practical converters operate at duty cycles $D$ between 0.2 and 0.8 , the resistance $R$ in (15) is replaced into (14) to obtain

$$
R=\frac{V_{o}^{2}}{I_{L} \cdot V_{\text {in }}} \text {. }
$$

By replacing (9) into (16), the following is obtained:

$$
R=\frac{V_{\text {in }}}{I_{L} \cdot(1-D)^{2}} .
$$




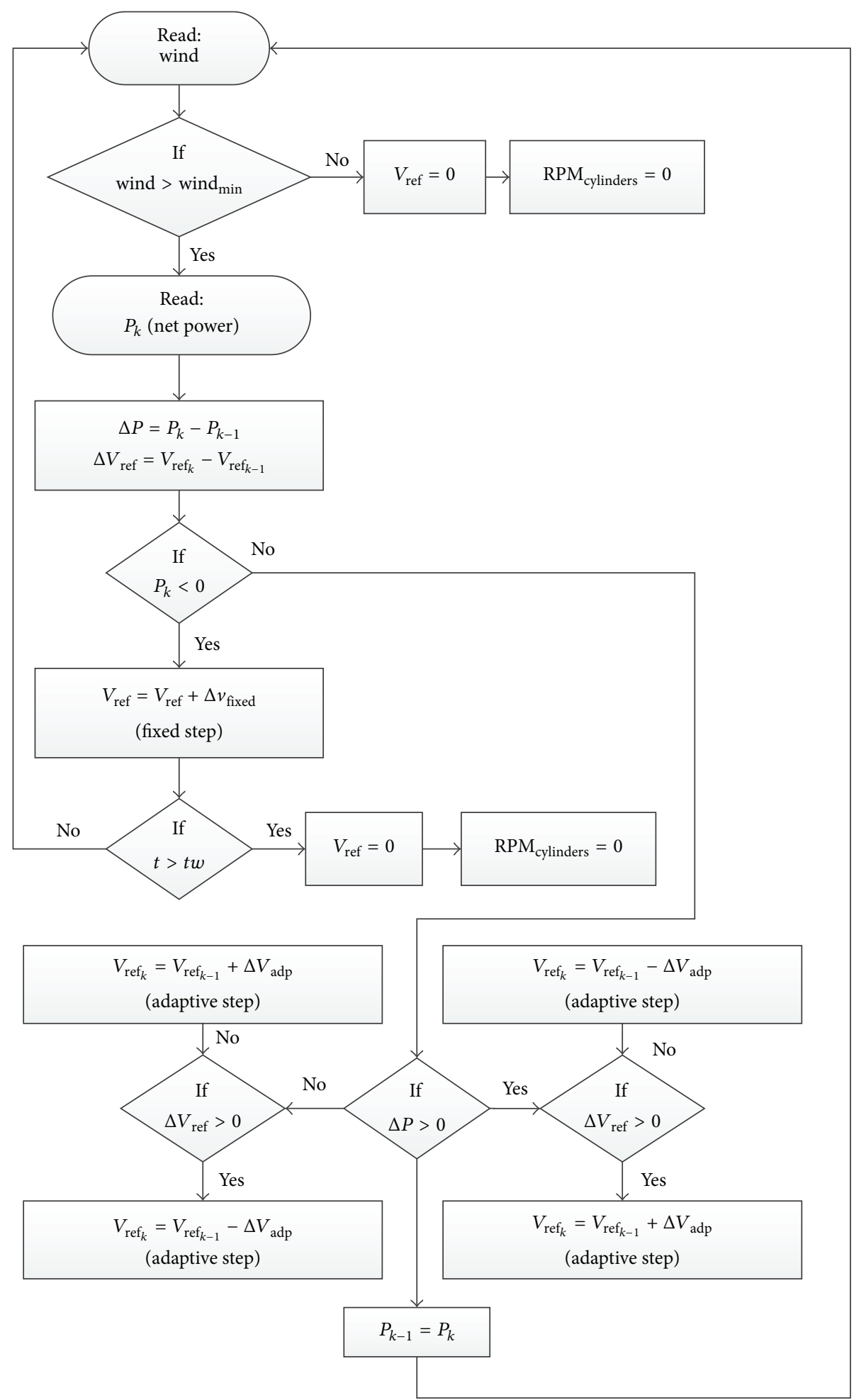

Figure 9: Algorithm flowchart to control the rotating cylinders.

The average input voltage $V_{\text {in }}$ is related to the peak input lineto-line voltage $V_{\mathrm{pk}}$ across the rectifier according to [23]

$$
V_{\text {in }}=2.34 \cdot \frac{V_{\mathrm{pk}}}{\sqrt{2} \cdot \sqrt{3}} .
$$

Therefore,

$$
R=\frac{2.34 \cdot\left(V_{\mathrm{pk}} /(\sqrt{2} \cdot \sqrt{3})\right)}{I_{L} \cdot(1-D)^{2}} .
$$


TABLE 2: Parameters of the BLDC motor.

\begin{tabular}{lc}
\hline Parameters & Value \\
\hline Rated power $[\mathrm{W}]$ & 180 \\
Rated speed $[\mathrm{RPM}]$ & 3000 \\
Continuous torque $[\mathrm{N} \cdot \mathrm{m}]$ & 0.57 \\
Supply voltage $V_{\mathrm{dc}}[\mathrm{V}]$ & 36 \\
Resistance $[\Omega]$ & 0.9 \\
Inductance $[\mathrm{mH}]$ & 2.0 \\
$V_{\text {rms }} / \mathrm{kRPM}$ & 8.9 \\
Number of poles & 4.0 \\
\hline
\end{tabular}

TABLE 3: PMSG generator.

\begin{tabular}{lc}
\hline & PMSG generator \\
Parameters & Value \\
\hline Rated power $[\mathrm{kW}]$ & 1.0 \\
Stator resistance $[\Omega]$ & 0.92 \\
Inductance $L_{d}[\mathrm{mH}]$ & 3.5 \\
Inductance $L_{q}[\mathrm{mH}]$ & 3.5 \\
$V_{\text {pk }}$ (line-to-line peak voltage)/kRPM & 157.2 \\
Number of poles & 14 \\
Gearbox & $1: 5$ \\
\hline
\end{tabular}

TABLE 4: Magnus turbine parameters.

\begin{tabular}{llc}
\hline Parameter & Description & Value \\
\hline$N$ & Number of cylinders & 6 \\
$R_{1}[\mathrm{~m}]$ & Radius of the turbine & 1.5 \\
$R_{2}[\mathrm{~m}]$ & Radius of the cylinders & 0.05 \\
$U_{\infty}$ & Wind speed [m/s] & Variable \\
$\Omega_{1}[\mathrm{RPM}]$ & Turbine speed & $0-260$ \\
$\Omega_{2}[\mathrm{RPM}]$ & Cylinders speed & $0-1318$ \\
Wind $_{\text {min }}$ & Minimum wind to generated $P_{\text {net }}$ & $4.2 \mathrm{~m} / \mathrm{s}$ \\
$\Delta V_{\text {fixed }}$ & Fixed step & 0.005 \\
$t_{w}(\mathrm{~s})$ & Maximum time with negative $P_{\text {net }}$ & 60 \\
\hline
\end{tabular}

\section{Simulation Results}

4.1. A. Simulations Parameters of the BLDC Motor and PMSG. Table 2 presents the main BLDC motor parameters used in the Magnus turbine prototype as shown in Figure 1. These parameters were extracted from the manufacturer's manual and used along with the simulations in PSIM [24]. The parameters of the PMSG generator were also taken from the manufacturer's manual according to Table 3.

4.2. Design Boost Converter and $R$ Load. Replacing the power coefficient (4) into the mechanical power (3) and using the values given in Table 4, one obtains the calculated mechanical power curves as displayed in Figure 10. These curves are related to the mechanical power generated by the Magnus turbine for three different wind speeds.

Figure 10 displays the maximum mechanical power and the respective turbine speed considering a gearbox ratio $(1: 5)$ to the PMSG generator rotation. Therefore, in Figure 10,

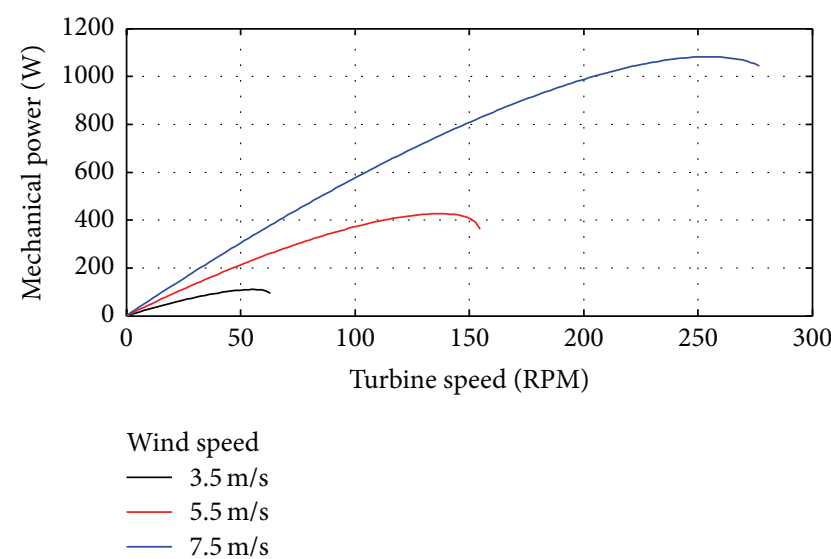

FIGURE 10: Turbine mechanical power versus $\Omega_{1}$ (TSR).

the PMSG speed provides the maximum mechanical power and with the PMSG constant $V_{\mathrm{pk}} / \mathrm{kRPM}$ in Table 3 is used to calculate $V_{\mathrm{pk}}$. With $V_{\mathrm{pk}}$ from (18) $V_{\text {in }}$ can be calculated. Neglecting the mechanical losses, the PMSG power is equal to $P_{\text {in }}$ and therefore the average inductor current $I_{L}$. Equation (19) is used to calculate the load resistance $R$.

Calculation of the Load Resistance $R$. The load resistance $R$ is calculated from (19) for intermediate values of wind speeds $(5.5 \mathrm{~m} / \mathrm{s})$ and the corresponding duty cycle for an intermediate value $D=0.5$. It is intended to obtain thereby the load resistance $R$ by varying the boost cycle ratio up or down from the generator point of view for the appropriate maximum power transfer within the upper and lower limits of wind speeds. Therefore, by increasing the duty cycle, the load resistance $R$ is seen by the generator output as a lower value, suitable for low powers (speeds lower than $5.5 \mathrm{~m} / \mathrm{s}$ wind). By decreasing the duty cycle, the load resistance $R$ ratio would be seen by the generator as a larger value, suitable for higher power (wind speeds greater than $5.5 \mathrm{~m} / \mathrm{s}$ ).

Using the data listed in Table 5 regarding a wind speed $5.5 \mathrm{~m} / \mathrm{s}$ results in $R=100.4 \Omega$.

Rewriting (17) results in

$$
D=1-\sqrt{\frac{V_{\text {in }}}{R \cdot I_{L}}} .
$$

Using (20) to calculate $I_{L}$ and $V_{\text {in }}$ for a wind speed $3.5 \mathrm{~m} / \mathrm{s}$ in Table 5 results in $D_{3.5}=0.61$. Using (20) for $I_{L}$ and $V_{\text {in }}$ and a wind speed $7.5 \mathrm{~m} / \mathrm{s}$ results in $D_{7.5}=0.42$.

Calculating the Boost Inductor L. The minimum inductance must be calculated for a lower converter input current using (12). Considering an input current of $2.7 \mathrm{~A}$, and assuming a ripple current of $0.5 \mathrm{~A}$, the converter switching frequency 
TABLE 5: Calculating the load resistance $R$.

\begin{tabular}{lcccccr}
\hline $\begin{array}{l}\text { Wind } \\
{[\mathrm{m} / \mathrm{s}]}\end{array}$ & $\begin{array}{c}\text { RPM } \\
\text { (turbine) } \\
\text { PMSG }\end{array}$ & $\begin{array}{c}\text { Mechanical } \\
\text { Power }[\mathrm{W}]\end{array}$ & $\begin{array}{c}\text { Voltage } \\
V_{\text {pk }} \\
{[\mathrm{V}]}\end{array}$ & $\begin{array}{c}\text { Voltage } \\
V_{\text {in }} \\
{[\mathrm{V}]}\end{array}$ & $\begin{array}{c}I_{L} \\
{[\mathrm{~A}]}\end{array}$ & $\begin{array}{c}\text { Load } R \\
{[\Omega]}\end{array}$ \\
\hline 3.5 & $(55) 275$ & 110 & 43.2 & 41.3 & 2.7 & - \\
5.5 & $(137) 685$ & 427 & 107.5 & 102.9 & 4.1 & $\mathbf{0 . 6 1}$ \\
7.5 & $(255) 1275$ & 1082 & 200.4 & 191.0 & 5.7 & $\mathbf{1 0 0 . 4}$ \\
\hline
\end{tabular}

TABLE 6: Components of the static converter.

\begin{tabular}{lcc}
\hline & Filters & \\
Parameters & Description & Values \\
\hline$C_{1}[\mathrm{uF}]$ & Capacitor & 1000 \\
$C_{f}[\mathrm{uF}]$ & Filter capacitor & 4000 \\
$L_{f}[\mathrm{mH}]$ & Filter inductance & 16 \\
$L[\mathrm{mH}]$ & Boost inductance & 3 \\
$C_{2}[\mathrm{uF}]$ & Capacitor & 470 \\
$R[\mathrm{ohms}]$ & Load resistance & 100.4 \\
\hline
\end{tabular}

would be $6 \mathrm{kHz}$, and the converter will operate at its minimum duty cycle of 0.2 :

$$
\begin{aligned}
\Delta i_{L} & =\frac{V_{\text {in }}}{2 \cdot L} \cdot D \cdot T_{S} \\
\therefore L_{\text {min }} & =\frac{41.3}{2 \cdot 0.5} \cdot 0.2 \cdot \frac{1}{6 k}=1.4 \mathrm{mH} .
\end{aligned}
$$

In this case one can use a higher inductance to ensure a CCM, even at lower currents, say $3.0 \mathrm{mH}$. Note that the switching frequency affects directly the inductance values.

Table 6 shows the values of the static converter filter parameters.

4.3. Simulation Results. In the simulated results a wind speed of $3.0 \mathrm{~m} / \mathrm{s}$ is initially applied which is insufficient to generate positive net power $\left(P_{\text {gen }}>0\right)$ and therefore the turbine remains static. Because of this low wind speed, the simulated wind system awaits for a minimum wind speed required for its operation $(4.2 \mathrm{~m} / \mathrm{s})$ so as to start up with a positive net power $P_{\text {gen }}$. At the instant $t=5 \mathrm{~s}$ a wind speed step of $4.5 \mathrm{~m} / \mathrm{s}$ is applied, until a wind speed of $7.5 \mathrm{~m} / \mathrm{s}$, which is able to produce a net power positive. Finally at the instant $t=65 \mathrm{~s} \mathrm{a}$ negative step of $-2.0 \mathrm{~m} / \mathrm{s}$ is applied letting the wind speed at $5.5 \mathrm{~m} / \mathrm{s}$.

Figure 11 represents the electrical power $P_{\text {gen }}$ at the output of the three-phase diode rectifier. It can be observed that the values $P_{\text {gen }}$ obtained from the electrical power generated in the simulation are quite close to the desired values of $P_{\text {gen }}$ given in Table 5. Therefore the load resistance $R$ and the design methodology are correct. By varying the duty cycle $\mathrm{PWM}_{2}$ of the boost converter it is maximized the conversion of mechanical power into electrical power, adequating so the speed control of the PMSG generator. The algorithm "HCC Cylinders" tracks the optimal cylinder speed with larger step increments whenever the net power is negative $P_{\text {net }}$. For such reason the electrical power $P_{\text {gen }}$ reaches positive values in a

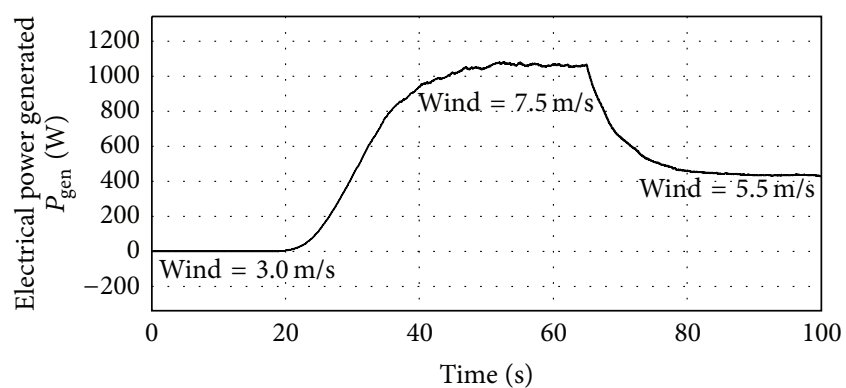

FIGURE 11: Electrical power generated for wind speed steps going from $3.0 \mathrm{~m} / \mathrm{s}$ to $7.5 \mathrm{~m} / \mathrm{s}$ and from $7.5 \mathrm{~m} / \mathrm{s}$ to $5.5 \mathrm{~m} / \mathrm{s}$.

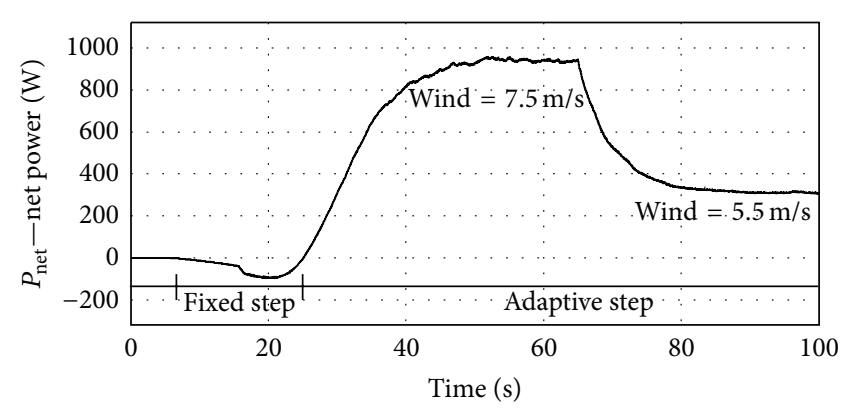

FIGURE 12: Net power for wind speed steps going from $3.0 \mathrm{~m} / \mathrm{s}$ to $7.5 \mathrm{~m} / \mathrm{s}$ and from $7.5 \mathrm{~m} / \mathrm{s}$ to $5.5 \mathrm{~m} / \mathrm{s}$.

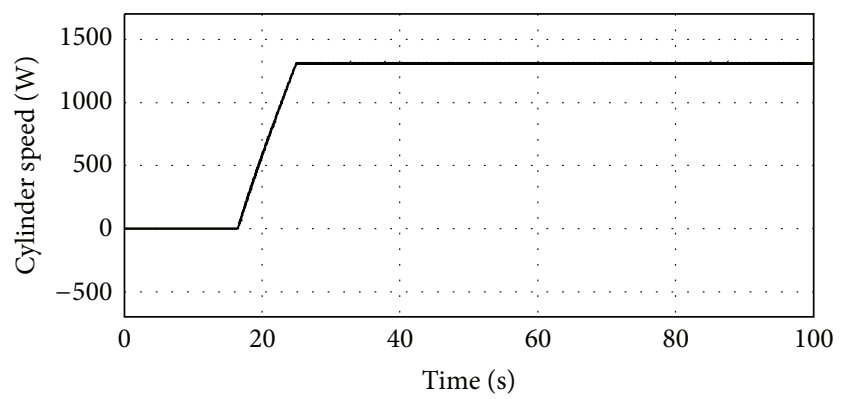

FIGURE 13: Cylinders speed.

relatively short time. The static converter components used in the simulation are ideal and therefore the electrical power $P_{o}$ in the load has the same waveform as that of $P_{\text {gen }}$.

Figure 12 is the graph of the net power $P_{\text {net }}$.

Figure 13 represents the cylinder rotating speed. The algorithm "HCC Cylinders" increments the duty cycle $\mathrm{PWM}_{1}$ that does not translate the rotational speed immediately until the three-phase inverter bridge reaches the minimum 


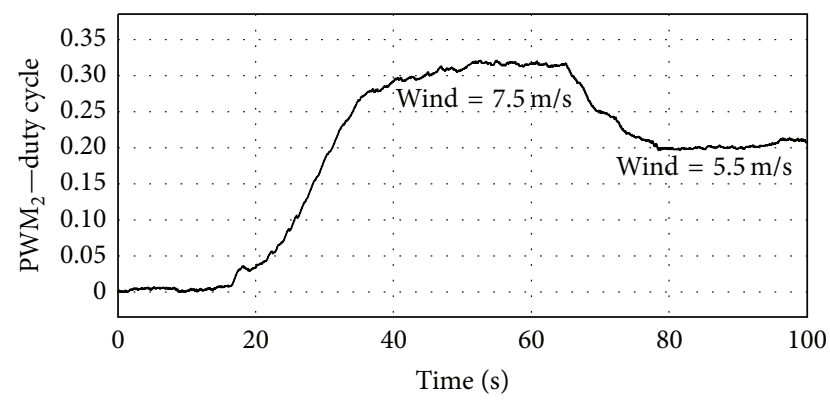

FIGURE 14: Boost converter duty cycle $\mathrm{PWM}_{2}$ for wind speeds of $3.0 \mathrm{~m} / \mathrm{s}, 7.5 \mathrm{~m} / \mathrm{s}$, and $5.5 \mathrm{~m} / \mathrm{s}$.

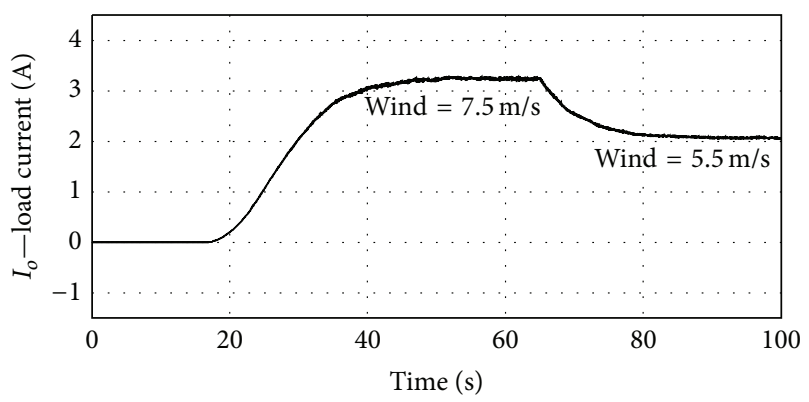

FIGURE 15: Load current $I_{o}$ for a wind speed $3.0 \mathrm{~m} / \mathrm{s}, 7.5 \mathrm{~m} / \mathrm{s}$, and $5.5 \mathrm{~m} / \mathrm{s}$.

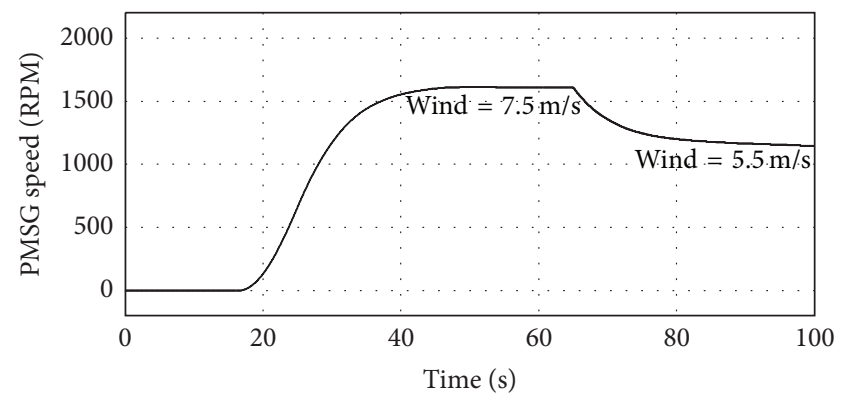

FIGURE 16: PMSG generator speed for wind speeds $3.0 \mathrm{~m} / \mathrm{s}, 7.5 \mathrm{~m} / \mathrm{s}$, and $5.5 \mathrm{~m} / \mathrm{s}$.

voltage applied across the BLDC motor terminals. The HCC algorithm increases the duty cycle $\mathrm{PWM}_{1}$ to increase the cylinder speed until it reaches its maximum point and remains at this maximum value for a wind speed of $7.5 \mathrm{~m} / \mathrm{s}$.

Figure 14 shows the HCC curve tracking the optimal boost-converter duty cycle $\mathrm{PWM}_{2}$ to deliver the maximum electrical power to load $R$.

Figure 15 represents the load current $I_{o}$ and the corresponding wind step responses with relative fewer oscillations due to the effectiveness of the $L_{f} C_{f}$ filter.

Figure 16 represents the generator speed with the algorithm "HCC Boost" for the $\mathrm{PWM}_{2}$ duty cycle increments and decrements to scan the MPPT optimal PMSG speed.

\section{Conclusions}

The simulation results presented in this paper refer to the maximum mechanical power as provided in Table 5 for wind speeds between $5.5 \mathrm{~m} / \mathrm{s}$ and $7.5 \mathrm{~m} / \mathrm{s}$ to reach the electrical generated power $P_{\text {gen }}$ and load electrical power $P_{o}$. These results prove that the control methodology applied to the boost and load resistor $R$ designs is correct as well as the specified values. The algorithms "HCC Cylinders" and "HCC Boost" effectively track the optimal cylinder rotation to provide the maximum net generated power $P_{\text {gen }}$ and the maximum load power $P_{o}$, respectively.

The Magnus wind system as discussed in this paper performs correctly the wind speed steps passing from $3.0 \mathrm{~m} / \mathrm{s}$ to $7.5 \mathrm{~m} / \mathrm{s}$ in order to increase the turbine mechanical power and wind speed steps passing from $7.5 \mathrm{~m} / \mathrm{s}$ to $5.5 \mathrm{~m} / \mathrm{s}$ in order to decrease the mechanical power, during the instants when performing the energy conversion and transfer of the maximum electrical power to the load.

\section{Conflict of Interests}

The authors declare that there is no conflict of interests regarding the publication of this paper.

\section{Acknowledgments}

The authors would like to thank CNPq (National Counsel of Technological and Scientific Development), CEESP-CTUFSM, and IFSC for the financial support during the development of this work.

\section{References}

[1] Y. Imai and C. Kato, "Research of cylinder with spiral fins for magnus wind turbine," Seisan Kenkyu, vol. 62, no. 1, pp. 5-9, 2010.

[2] B. R. Munson, D. F. Young, T. H. Okiishi, and W. W. Huebsch, Fundamentals of Fluid Mechanics, John Wiley \& Sons, 8th edition, 2009.

[3] F. M. White, Fluid Mechanics, McGraw-Hill, 4th edition, 2012.

[4] V. Nelson, Wind Energy: Renewable Energy and the Environment, CRC Press, 2009.

[5] http://www.mecaro.jp/eng/.

[6] N. Murakami and J. Ito, "Magnus Type Wind Power Generator," United States Patent. US7.504.740 B2, 2009.

[7] N. M. Bychkov, A. V. Dovgal, and V. V. Kozlov, "Magnus wind turbines as an alternative to the blade ones," Journal of Physics: Conference Series, vol. 75, no. 1, Article ID 012004, 2007.

[8] N. Bychkov, A. Dovgal, and A. Sorokin, "Parametric optimization of the magnus wind turbine," in Proceedings of the International Conference on Methods of Aerophysical Research (ICMAR '08), Akademgorodok, Russia, June-July 2008.

[9] N. M. Bychkov, "Magnus wind turbine, calculated characteristics of the wind wheel," Thermophysics and Aeromechanics, vol. 15, no. 2, 2008.

[10] J. G. Slootweg, S. W. H. de Haan, H. Polinder, and W. L. Kling, "General model for representing variable speed wind turbines in power system dynamics simulations," IEEE Transactions on Power Systems, vol. 18, no. 1, pp. 144-151, 2003. 
[11] D. Luo, D. Huang, and G. Wu, "Analytical solution on Magnus wind turbine power performance based on the blade element momentum theory," Journal of Renewable and Sustainable Energy, vol. 3, Article ID 033104, 2011.

[12] X. Sun, Y. Zhuang, Y. Cao, D. Huang, and G. Wu, "A threedimensional numerical study of the Magnus wind turbine with different blade shapes," Journal of Renewable and Sustainable Energy, vol. 4, no. 6, Article ID 063139, 2012.

[13] T. Burton, N. Jenkins, D. Sharpe, and E. Bossanyi, Wind Energy Handbook, John Wiley \& Sons, New York, NY, USA, 2nd edition, 2011.

[14] A. Monroy and L. Alvarez-Icaza, "Real-time identification of wind turbine rotor power coefficient," in Proceedings of the 45th IEEE Conference on Decision and Control, pp. 3690-3695, IEEE, San Diego, Calif, USA, December 2006.

[15] M. G. Simões and F. A. Farret, Renewable Energy Systems. Design and Analysis with Induction Generators, CRC Press, 2004.

[16] S. Russel and P. Norvig, Artificial Intelligence-A Modern Approach, Pearson Education, New York, NY, USA, 3rd edition, 2010.

[17] K. Han and G.-Z. Chen, "A novel control strategy of wind turbine MPPT implementation for direct-drive PMSG wind generation imitation platform," in Proceedings of the IEEE 6th International Power Electronics and Motion Control Conference (IPEMC '09), pp. 2255-2259, May 2009.

[18] X. Yang, X. Gong, and W. Qiao, "Mechanical sensorless maximum power tracking control for direct-drive PMSG wind turbines," in Proceedings of the IEEE Energy Conversion Congress and Exposition, pp. 4091-4098, IEEE, Atlanta, Ga, USA, September 2010.

[19] R.-Y. Duan, C.-Y. Lin, and R.-J. Wai, "Maximum-powerextraction algorithm for grid-connected PMSG wind generation system," in Proceedings of the 32nd Annual Conference on IEEE Industrial Electronics (IECON '06), pp. 4248-4253, IEEE, Paris, France, November 2006.

[20] L. C. Corrêa, J. M. Lenz, C. G. Ribeiro, J. G. Trapp, and F. A. Farret, "Maximum power point tracking for magnus wind turbines," in Proceedings of the 39th Annual Conference of the IEEE Industrial Electronics Society (IECON '13), pp. 1718-1722, IEEE, Vienna, Austria, November 2013.

[21] R. Krishnan, Permanent Magnet Synchronous and Brushless DC Motor Drives, CRC, 2010.

[22] J. C. U. Peña, M. A. G. Brito, G. A. Melo, and C. A. Canesin, "A comparative study of MPPT strategies and a novel singlephase integrated buck-boost inverter for small wind energy conversion systems," in Proceedings of the Brazilian Power Electronics Conference (COBEP '11), pp. 458-465, IEEE, Praiamar, Brazil, September 2011.

[23] I. Barbi, Power Electronics, UFSC, 6th edition, 2006.

[24] UFSM license, http://powersimtech.com/products/psim/.

[25] Prototype, https://www.youtube.com/watch?v=el33RqWtxc4. 


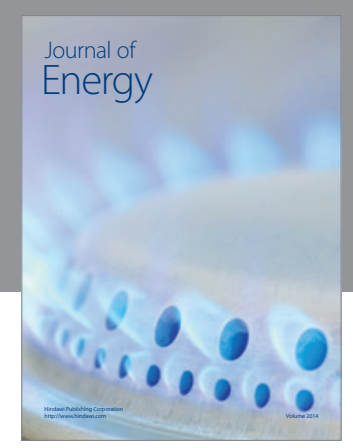

Journal of

Industrial Engineering
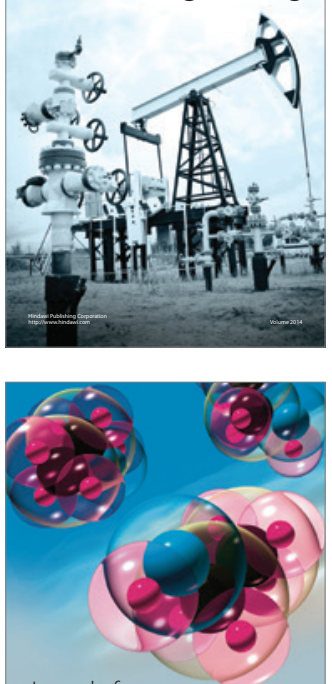

Fuels
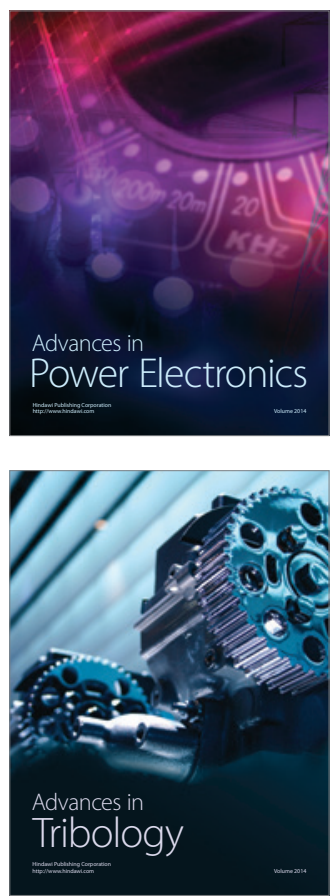

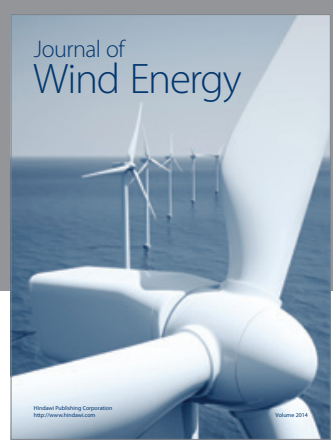

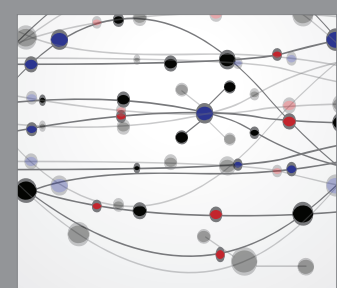

The Scientific World Journal

Submit your manuscripts at http://www.hindawi.com

Journal of

Structures
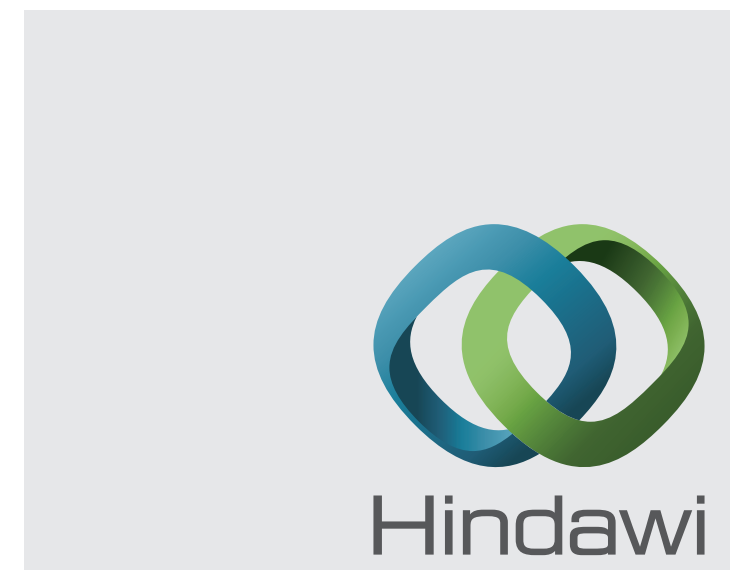

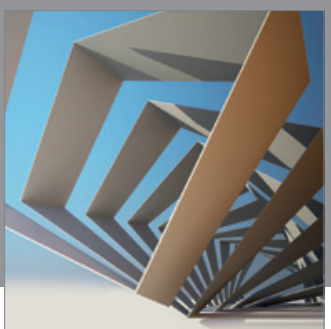

Rotating

Machinery
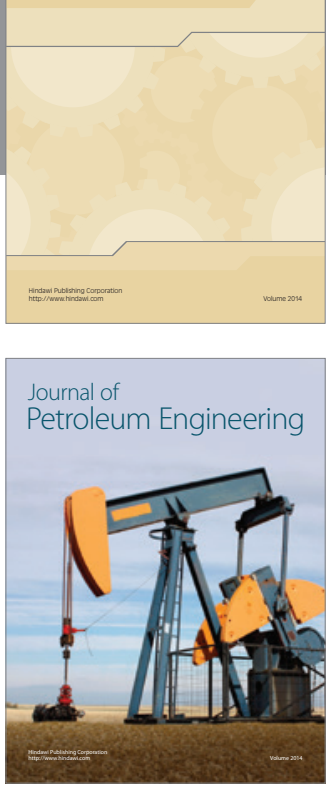

Journal of

Solar Energy
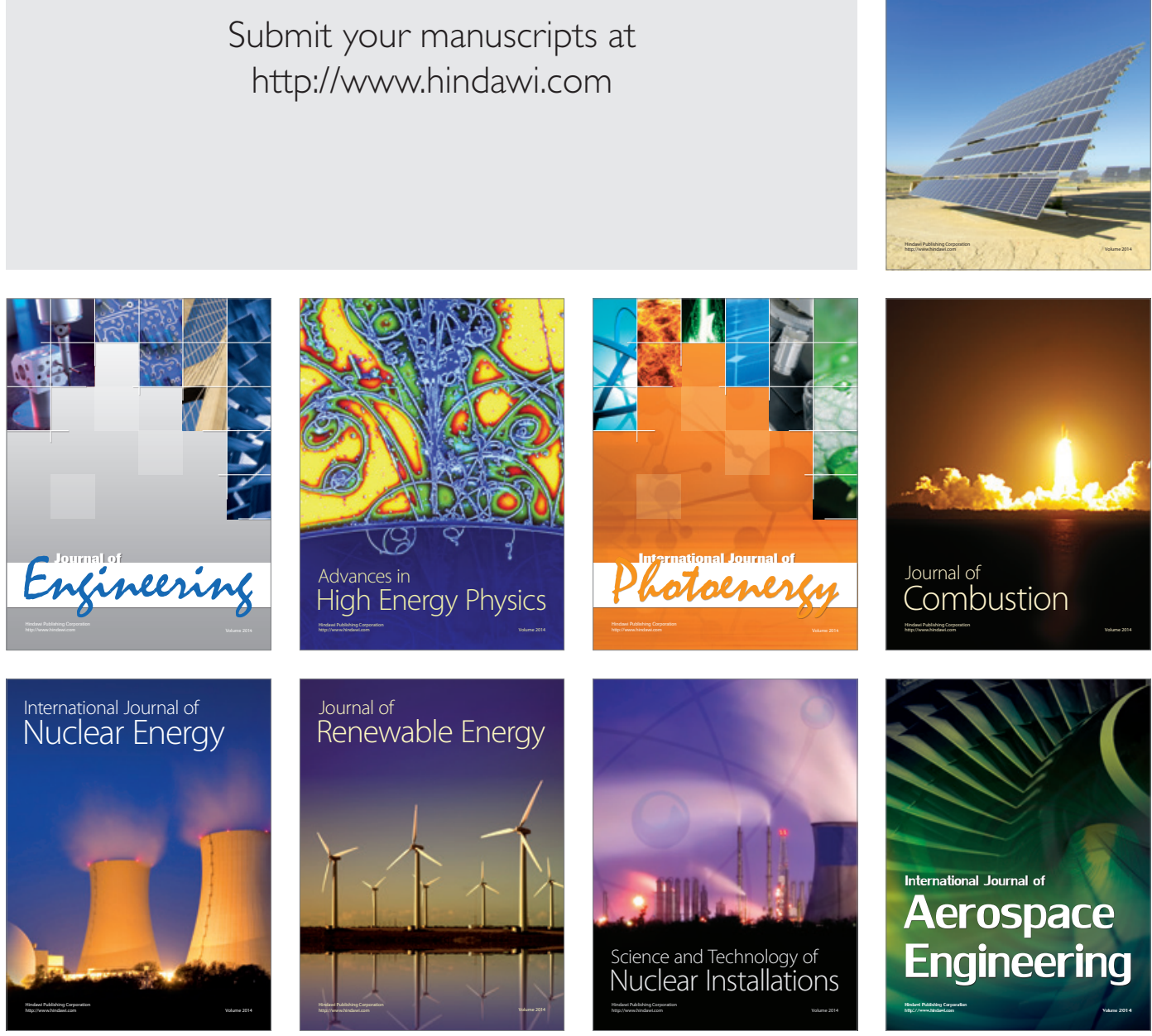